\title{
The Red Admiral butterfly (Vanessa atalanta, Lepidoptera: Nymphalidae) is a true seasonal migrant: an evolutionary puzzle resolved?
}

\author{
KAURI MIKKOLA
}

Finnish Museum of Natural History, P.O. Box 17, FIN-00014 University of Helsinki, Finland; e-mail: kauri.mikkola@helsinki.fi

Key words. Red Admiral, Vanessa atalanta, Monarch, Danaus plexippus, butterflies, Lepidoptera, migrations, air currents

\begin{abstract}
Ornithologists in Finland recorded the autumn migration of the Red Admiral butterfly, Vanessa atalanta (L.). In the best year, 1998, 1240 migrants were counted from a bird tower in September. That is, half a million butterflies migrated over a 100-km front. The butterflies were flying above forests riding on cool northerly winds. Radar indicated that a large proportion migrated at high elevations outside the visible range. These records help to resolve an "evolutionary puzzle" of why migrant butterflies and moths travel to northern latitudes when their offspring have limited possibilities of returning south. Until now, the only butterfly for which a high-elevation return migration on northerly winds is known is the American Monarch Danaus plexippus (L.).
\end{abstract}

\section{INTRODUCTION}

Why do some butterflies and moths fly year after year to northern latitudes to reproduce? Early students of insect migration believed that the northern migrants represented an 'overproduction' of southern populations that is supposedly lost during migration (Williams, 1958; Johnson, 1969). The American Monarch (Danaus plexippus) was thought to be the only species that utilizes northerly winds to migrate south (Urquhart, 1960; Gibo, 1986; Brower, 1996). Now the binoculars and telescopes of ornithologist's have revealed that the Red Admiral (Vanessa atalanta), too, returns south by riding high up on northerly winds.

In the summer, several species of migrant butterflies and moths appear in northern Europe. These migrants escape the summer drought of southern regions and are able to take advantage of the huge areas of lush vegetation in the north. But their offspring are unlikely to hibernate in the north yet there are no observations of significant numbers of them flying south.

It is an old idea that insects may take advantage of the high speed winds at high elevations (Felt, 1925). Radar has shown that these migrants are able to orientate themselves at high altitudes (Riley \& Reynolds, 1986; Drake \& Farrow, 1988). The observations in Finland of Red Admirals (Vanessa atalanta) flying south led to more thorough observations in the mid-1990s.

\section{THE OBSERVATIONS}

A group of ornithologists agreed to record butterfly migrants from a bird tower located $35 \mathrm{~km} \mathrm{SW}$ of Helsinki, Finland, on the northern coast of the Gulf of Finland (Mikkola, 2003). Butterflies flying with clear and persistent orientation over the forests were counted over a front estimated to be $500 \mathrm{~m}$ wide and $100 \mathrm{~m}$ high.

In September 1998, 1240 Red Admirals passed the tower, of which 404 were observed on 3 September. The butterflies were flying above the forest in a southerly direction on northerly winds, except for 20 individuals that flew in northwesterly direction on a day when the wind veered to the southeast. No migrations were observed on warm days with southerly winds; many Red Admirals flew up but dropped down again.

Over a five-day period in September 2000 at a nearby bird observatory, on the two days with northerlies 65 Red Admirals were migrating south high up in the sky, but on the three warmer days with southerly winds, all of the 52 individuals seen rested or were on the wing along a bird count transect.

During the migration of Red Admirals, the meteorological radar at the University of Helsinki recorded numbers of "beesized targets", probably Red Admirals (because the field observations reported only Red Admirals in that size class), riding on the wind at an altitude of up to $2000 \mathrm{~m}$, where the temperature ranged between +2 and $+3^{\circ} \mathrm{C}$. Some individuals were temporarily flying at even higher altitudes.

\section{DISCUSSION}

With an even migration flow, and assuming that every second butterfly was detected, the $100 \mathrm{~km}$ coastal strip where observations were made was traversed by half a million Red Admirals in September 1998. The radar indicated that many more were flying higher up.

By comparing the time of the peak migration in Finland (Mikkola, 2003) with that of the peak arrival of butterflies in Spain in the same year (Stefanescu, 2001), it appears that the Red Admirals needed around five weeks to fly the $3000 \mathrm{~km}$ from Northern Europe to the Mediterranean.

It now appears that both the Red Admiral and the Monarch perform their main return migration riding at medium to high elevations on northerly air currents (Brower, 1996; Mikkola, 2003). The flights of the Red Admirals at low elevations against the wind, frequently observed in Central and Southern Europe (Stefanescu, 2001; Tucker, 1997; Benvenuti et al., 1994), and of Monarchs in North America (Gibo, 1986), possibly occur when suitable tailwinds are lacking.

Monarchs do not reproduce during winter in Mexico or California, but they are partly active, and mating activity increases in spring (Brower, 1996). Red Admirals do not diapause either, and have to feed about once a week; the northernmost area where successful reproduction of overwintering Red Admirals is observed is southwesternmost Germany (Hensle, 2001).

Red Admirals do not form aggregations like Monarchs. The larval host plant of the Monarch, the milkweed (Asclepias), does not grow where the adults hibernate, and the Monarchs migrate northward in spring to areas where milkweed plants grow (Brower, 1996).

The ecological strategy of the Red Admiral differs from that of the Monarch in that a substantial proportion of the Red Admirals lay eggs late in autumn, after arrival from the north 


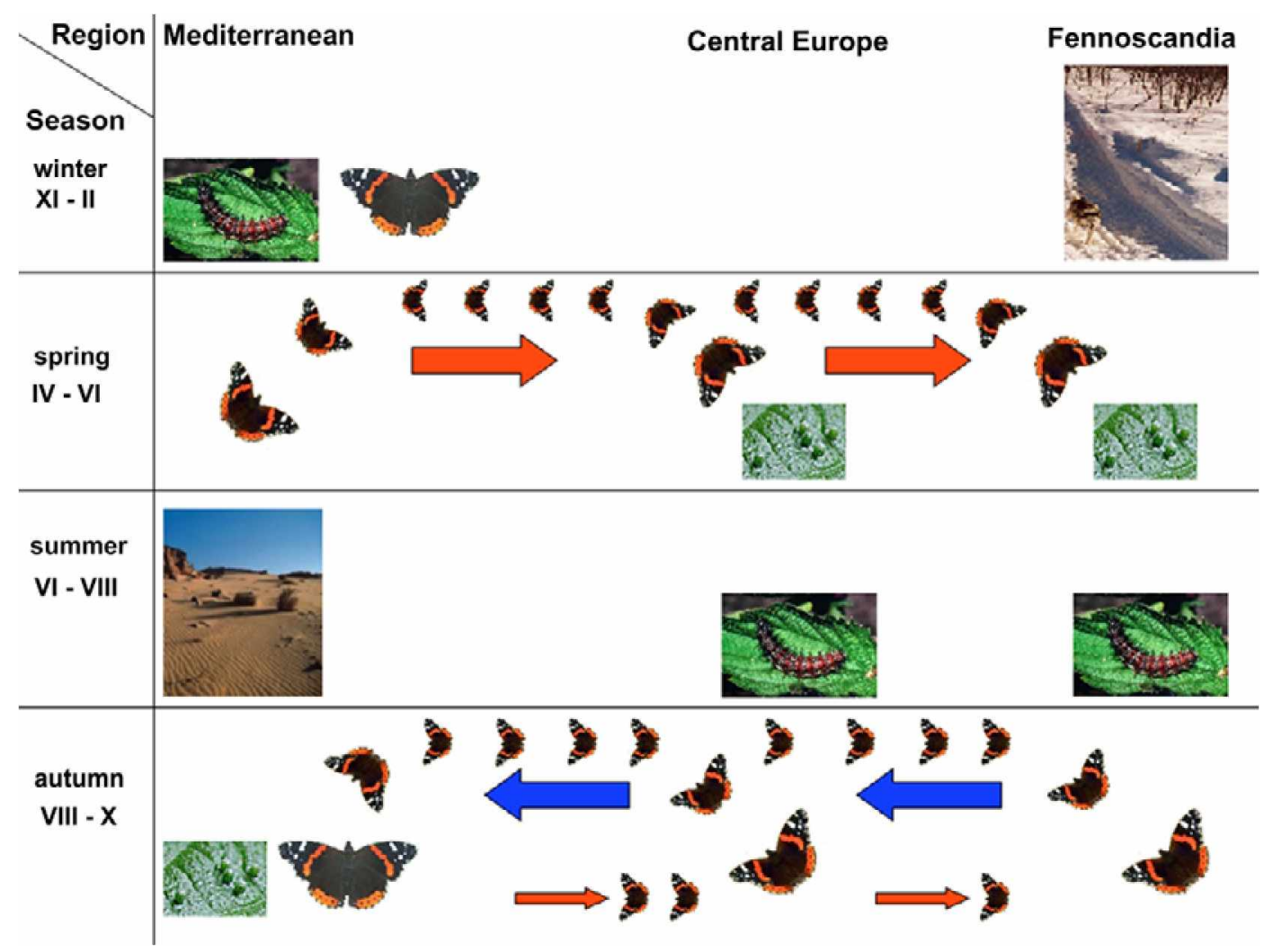

Fig. 1. The seasonal migration patterns of the Red Admiral in Europe. Large horizontal butterflies = hibernating specimens, smaller oblique ones $=$ migrating butterflies. Large arrows $=$ high-elevation, small $=$ low-elevation winds; red $=$ warm, blue $=$ cool . Central Europe is an example of shorter alternatives.

(Stefanescu, 2001; cf. Fig. 1). Thus while some adults hibernate, the offspring of others grow slowly on nettles (Urtica).

When the Red Admirals leave Spain, the summer drought has started and the nettles are withering (Stefanescu, 2001). In Finland in early June, when the main migration arrives, the nettles are growing rapidly. When in late September to early November the main wave of Red Admirals returns to Spain, the nettles are again growing.

These new observations strongly suggest that the Red Admiral is a true seasonal migrant like the Monarch butterfly. In these butterflies there occur similar interplay between migrations and air currents, and the phenologies of the larval host plants. In the Red Admiral, several phenomena remain to be investigated, including the relationships between the highelevation tailwind and low-elevation headwind flights, the mechanisms of orientation, the physiology of feeding and reproduction, and the genetics of the migratory behaviour.

ACKNOWLEDGEMENTS. I am grateful to all the ornithologists and lepidopterologists who have made their observations available to me. I would like to thank the following scientists from the University of Helsinki: Mr Matti Leskinen for the radar data, Dr Larry Huldén for help in constructing the illustration, and Prof Ilkka Hanski for several valuable suggestions.

\section{REFERENCES}

Benvenuti S., Dall'Antonia P. \& Ioale P. 1994: Migration pattern of the red admiral, Vanessa atalanta L. (Lepidoptera: Nymphalidae), in Italy. Boll. Zool. 61: 343-351.

Brower L.P. 1996: Monarch butterfly orientation: missing pieces of a magnificent puzzle. J. Exp. Biol. 199: 93-103.
DRAKE V.A. \& Farrow R.A. 1988: The influence of atmospheric structure and motions on insect migration. Annu. Rev. Entomol. 33: 183-210.

Felt E.P. 1925: Dispersal of butterflies and other insects. Nature 116: 365-368.

Grio D.L. 1986: Flight strategies of migrating monarch butterflies (Danaus plexippus L.) in southern Ontario. In: Danthanarayana W. (ed.): Insect Flight: Dispersal and Migration. Springer Verlag, Berlin, Heidelberg, pp. 172-184.

HeNSLE J. 2001: Die Überwinterung von Vanessa atalanta (Linnaeus, 1758) am Kaiserstuhl (Südwestdeutschland) (Lepidoptera: Nymphalidae). Atalanta 32: 379-388.

Johnson C.G. 1969: Migration and Dispersal of Insects by Flight. Methuen, London, 763 pp.

MikKola K. 2003: Red Admiral Vanessa atalanta (Lepidoptera: Nymphalidae) selects northern winds on southward migration. Entomol. Fennica 14: 15-24.

RILEY J.R. \& ReYNoLDS D.R. 1986: Orientation at night by highflying insects. In: Danthanarayana W. (ed.): Insect Flight: Dispersal and Migration. Springer Verlag, Berlin, Heidelberg, pp. 71-87.

STEFANESCU C. 2001: The nature of migration in the red admiral butterfly Vanessa atalanta: evidence from the population ecology in its southern range. Ecol. Entomol. 26: 525-536.

TUCKER M. 1997: The Red Admiral Butterfly. Butterfly Conservation, Colchester, $32 \mathrm{pp}$.

URquirart F.A. 1960: The Monarch Butterfly. University of Toronto Press, Toronto, $361 \mathrm{pp}$.

Williams C.B. 1958: Insect Migration. Collins, London, 235 pp.

Received May 13, 2003; revised June 25, 2003; accepted August 21, 2003 